ARTICLE

\title{
Cysteine-specific protein multi-functionalization and disulfide bridging using 3-bromo-5-methylene pyrrolones
}

Yingqian Zhang (1) 1,3, Chuanlong Zang ${ }^{1,3}$, Guoce An ${ }^{2}$, Mengdi Shang ${ }^{1}$, Zenghui Cui ${ }^{1}$, Gong Chen (iD ${ }^{1}, Z_{\text {hen }} \mathrm{Xi}^{1} \&$ Chuanzheng Zhou (10) ${ }^{1 \times}$

Many reagents have been developed for cysteine-specific protein modification. However, few of them allow for multi-functionalization of a single Cys residue and disulfide bridging bioconjugation. Herein, we report 3-bromo-5-methylene pyrrolones (3Br-5MPs) as a simple, robust, and versatile class of reagents for cysteine-specific protein modification. These compounds can be facilely synthesized via a one-pot mild reaction and they show comparable tagging efficiency but higher cysteine specificity than the maleimide counterparts. The addition of cysteine to $3 \mathrm{Br}-5 \mathrm{MPs}$ generates conjugates that are amenable to secondary addition by another thiol or cysteine, making 3Br-5MPs valuable for multi-functionalization of a single cysteine and disulfide bridging bioconjugation. The labeling reaction and subsequent treatments are mild enough to produce stable and active protein conjugates for biological applications.

\footnotetext{
${ }^{1}$ State Key Laboratory of Elemento-Organic Chemistry and Department of Chemical Biology, College of Chemistry, Nankai University, Tianjin 300071, China. ${ }^{2}$ Department of Forensic Chemistry, Criminal Investigation Police University of China, Liaoning, Shenyang 110854, China. ${ }^{3}$ These authors contributed equally:

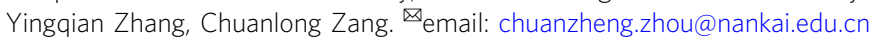


C ysteine modification is a practical approach for producing functionalized proteins and has found widespread biomedical applications ${ }^{1-3}$. Unpaired, free cysteine, which generally exhibits high nucleophilicity, is relatively rare in proteins and is therefore an ideal site for chemoselective protein modification. Accessible free cysteine residues can be readily introduced by site-directed mutagenesis. Cysteine-specific modification is typically achieved by reaction of the thiol group with electrophiles such as maleimides, iodoacetamides, alkyl halides, and pyridyl disulfides ${ }^{4,5}$. Recently, the need to prepare homogeneous antibody-drug conjugates has inspired a wave of interest in exploring cysteine-specific bioconjugation reagents with improved reactivity, specificity, stability, and biocompatibility ${ }^{6,7}$. To this end, maleimide derivatives ${ }^{8-10}$, dehydroalanine ${ }^{11,12}$, perfluoroaromatic reagents ${ }^{13-16}$, organometallic palladium reagents ${ }^{17,18}$, and many others $^{19-23}$ have been developed, and each of these reagents shows unique merits. However, only a few of them permit multifunctionalization of a single Cys residue $22,24,25$, which would be advantageous in certain situations.

In proteins, disulfide bonds are more common than free cysteines, and disulfide reduction followed by rebridging bioconjugation offers another approach for chemoselective modification of proteins and is especially attractive for functionalization of immunoglobulin G (IgG), an antibody that has four reducible interchain disulfides but no free cysteine ${ }^{25-28}$. Many reagents, including bromomaleimides ${ }^{29,30}$, bromopyridazinediones ${ }^{27,31-33}$, bis-sulfones and allyl sulfones $24,26,34$, and divinylpyrimidine ${ }^{28}$, have been developed for such applications. Nevertheless, seldom of them meet the requirements of simplicity, robustness, and high efficiency.

Recently, we reported that 5-methylene pyrrolones (5MPs) are promising protein-modification reagents ${ }^{10}$. These compounds are easy to prepare, stable, and highly thiol-specific. 5MP-protein conjugates can undergo traceless loss of the 5MP moiety when the $\mathrm{pH}$ is increased or when they are subjected to thiol-exchange conditions, thus making 5MPs valuable for reversible protein modification. Herein, we report that 3 -bromo-5MPs (3Br-5MPs), derivatives of $5 \mathrm{MPs}$, nevertheless exhibit different cysteinespecific protein bioconjugation behavior (Fig. 1). These brominated analogs retain merits of 5MPs such as easy preparation and high thiol-specificity but show improved reactivity toward cysteine. In addition, protein-3Br-5MP conjugates can undergo addition reactions with another thiol group, which makes $3 \mathrm{Br}$ $5 \mathrm{MPs}$ valuable tools for multi-functionalization of a single cysteine residue and disulfide bridging bioconjugation. The obtained adducts can be reduced under mild conditions to generate stable and biologically active conjugates. We demonstrate that $3 \mathrm{Br}-5 \mathrm{MPs}$ are simple and robust reagents for protein mono-, multi-functionalization, and disulfide bridging bioconjugation.

\section{Results}

Preparation of $3 \mathrm{Br}-5 \mathrm{MPs}$. $3 \mathrm{Br}-5 \mathrm{MPs}$ were first synthesized by means of the same strategy used for $5 \mathrm{MPs}^{10,35}$. Specifically, a variety of primary amine substrates $(\mathbf{2 a}-\mathbf{g})$ were coupled with intermediate $\mathbf{1}^{\prime}$ in neutral aqueous solution to furnish the corresponding 3Br-5MPs (3a-g) in modest yields (Method 1 in Table 1). We also prepared 3Br-5MPs from 4-bromo-furfuryl acetate (4) via a one-pot reaction. Oxidation of 4 by $N$-bromosuccinimide (NBS) gave the intermediate $\mathbf{1}^{\prime} 36,37$, which was in situ trapped by $\mathbf{2 a}-\mathbf{g}$ to provide the corresponding 3Br-5MPs (Method 2 in Table 1). Method 2 was more facile than method 1 and afforded 3Br-5MPs in higher yields.

We assessed the stability of the $3 \mathrm{Br}-5 \mathrm{MPs}$ by incubating 3a under various conditions and found that it, similar to the $5 \mathrm{MP}$ counterpart 5 (Fig. 2), was completely stable over the course of a 5 -day incubation period in a relatively wide $\mathrm{pH}$ range (6.0-9.5). In contrast, maleimide analog 6 decomposed rapidly under these conditions (Supplementary Figs. 22 and 23). Hence, 3Br-5MPs can be more easily prepared and are more stable than the widely used cysteine-specific bioconjugation reagents-maleimides.

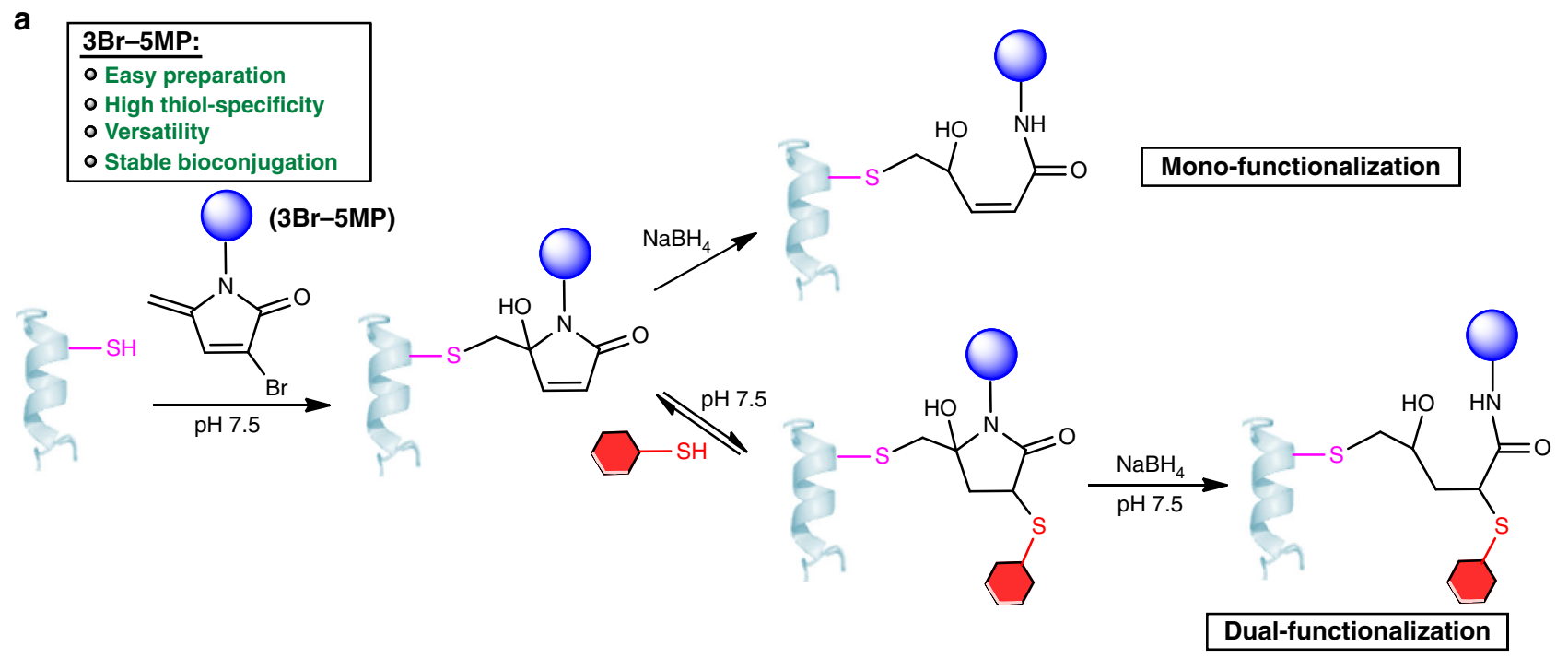

b

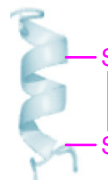
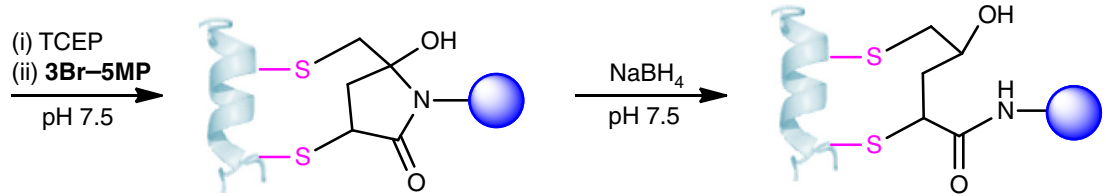

Disulfide bridging

bioconjugation

Fig. 1 Use of 3-bromo-5-methylene pyrrolones (3Br-5MPs) as versatile reagents for cysteine-specific protein modification. a Protein monofunctionalization and dual-functionalization using 3Br-5MP. b Disulfide bridging bioconjugation of protein using 3Br-5MP. 

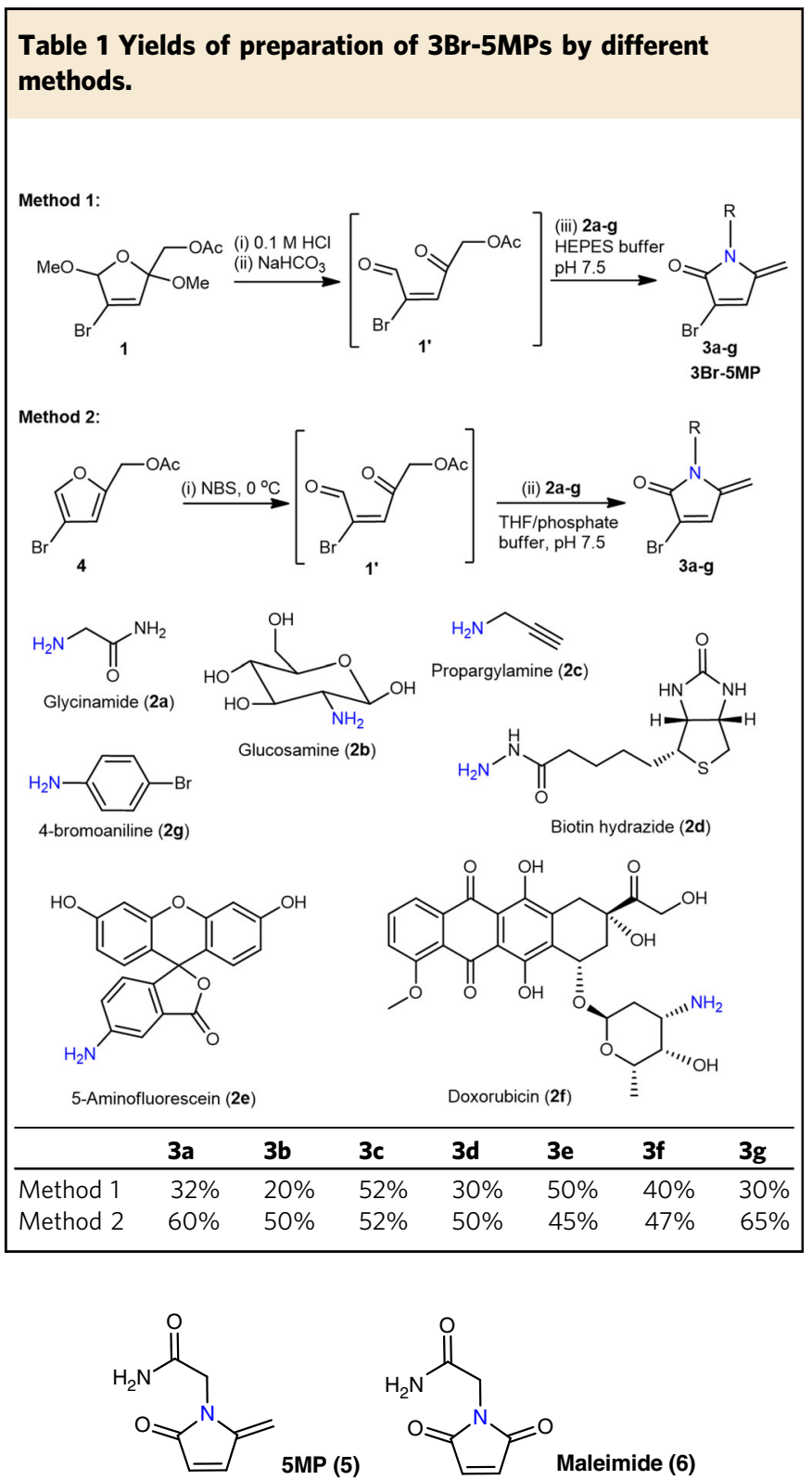

Fig. 2 Analogues of 3Br-5MP used for comparison in this study. Structures of 5MP (5) and maleimide (6).

Reactivity of 3Br-5MPs toward thiols. The reactivity of the $3 \mathrm{Br}$ $5 \mathrm{MPs}$ toward thiol groups was evaluated with $\mathbf{3 a}$ as a model compound. Treatment of 3a with 5 equiv of $\mathrm{EtSH}$ in neutral aqueous solution at $37^{\circ} \mathrm{C}$ for 5 min generated $\alpha, \beta$-unsaturated lactam 7 as the sole product (Fig. 3a). To fully characterize the structure of EtSH-3Br-5MP adducts, 8 was prepared and its structure was determined by X-ray diffraction analysis (Fig. 3b). The $S$-ethyl moiety is attached at the C6 position, suggesting that just like $5 \mathrm{MP}$, the addition of thiols to $3 \mathrm{Br}-5 \mathrm{MPs}$ occurs via 1, 6addition. The loss of the $\mathrm{C} 3-\mathrm{Br}$ atom and appearance of the $\mathrm{C} 5$ $\mathrm{OH}$ group in compound $\mathbf{8}$ point to an addition-elimination mechanism.

Unlike thiol-maleimide adducts and thiol-5MP adducts, which decompose rapidly via hydrolysis and/or retro-Michael reactions ${ }^{10,38}, 7$ was stable for up to 2 days in aqueous solution at $\mathrm{pH}$ 6.0-8.5 (Supplementary Fig. 24). However, we found 7 was reactive toward thiols. Treatment of 7 with excess EtSH (20 equiv) quantitatively generated dual-adducts 9 as a pair of diastereoisomers in $30 \mathrm{~min}$ (Fig. 3c). This result suggests that addition of EtSH to 7 was considerably slower than the addition of EtSH to $\mathbf{3 a}\left(k_{2} \ll k_{1}\right)$; otherwise, a mixture of $\mathbf{7}$ and $\mathbf{9}$ would have been obtained in the latter case.

Where the second EtSH is anchored in 9 could not be determined by nuclear magnetic resonance (NMR) at this stage because of the complexity of the isomers. This could, however, be confirmed after their transformation to reduced forms (see below), which subsequently showed that the second EtSH was introduced at the $\mathrm{C} 3$ position. This suggests that a carbonyl function may be in situ generated at the C5 position during the addition of EtSH to the mono-adduct 7. Taken together, we proposed the following mechanism for the reaction between thiols and 3Br-5MPs: the primary addition of one thiol to $3 \mathrm{Br}$ 5MP generates a highly electrophilic intermediate 10 (Fig. 3d), which is attacked by hydroxide, followed by elimination of the $\mathrm{C} 3-\mathrm{Br}$ to give a stable mono-adduct (11). Compound 11 itself, an a, $\beta$-unsaturated amide, is not a good Michael acceptor ${ }^{39}$, but it can isomerize to a ring-open form (12). In the intermediate 12, Michael addition of thiol to the $\mathrm{C} 3$ position is supposed to be much favorable than an addition to the $C 4$ position, given that $\alpha$, $\beta$-unsaturated ketones are much better Michael acceptors than $\alpha$, $\beta$-unsaturated amides ${ }^{39,40}$. Therefore, Michael addition of another thiol to the C3 position of $\mathbf{1 2}$ gives an enolate intermediate $\mathbf{1 2}$, which is subjected to isomerization and a subsequent intramolecular ring-close reaction, providing the dual-adduct 13. Given that mono-adduct 7 was complete stable after incubation in neutral buffers for $48 \mathrm{~h}$ and no ring-open products were detected (Supplementary Fig. 24), isomerization of $\mathbf{1 1}$ to the ring-open form $\mathbf{1 2}$ is likely unfavorable and thus $\mathbf{1 2}$ exists in a trace amount. This indicates that ring-open is the ratelimiting step and explains, at least partly, why the secondary addition $\left(k_{2}\right)$ is much slower than the primary one $\left(k_{1}\right)$.

We found the dual-adduct 9 was liable to thiol-exchange reaction. Treating 9 with 20 equiv. of $\beta$-mercaptoethanol (BME) gave 14 slowly (Fig. 4a). This thiol-exchange reaction suggests that the dual-adduct $\mathbf{9}$ is not stable and the Michael addition of thiols to the mono-adduct 7 is reversible. That is, isomerization of 9 to the open-ring form (15) leads to the elimination of EtSH via a retro-Michael reaction to give the intermediate 16. Michael addition of $\mathrm{BME}$ to $\mathbf{1 6}$ generates the observed product 14 (Fig. 4b). In this regard, we proposed that reduction of the C5ketone in $\mathbf{1 5}$ to hydroxyl may significantly retard the elimination reaction and thus transfer the dual-adduct to a stabilized form. Thus, 9 was treated with 1.3 equiv. of $\mathrm{NaBH}_{4}$ in $\mathrm{pH} 7.5$ buffer and it was quantitatively reduced to 17 in minutes (Fig. 4c). The major isomer of $\mathbf{1 7}$ was isolated and fully characterized by NMR, which revealed that the second EtSH was introduced at the $\mathrm{C} 3$ position (Supplementary Figs. 16-18). Compound 17 was stable and no decomposition was observed after incubation in $\mathrm{pH} 7.5$ buffer for $48 \mathrm{~h}$ (Supplementary Fig. 25). Similarly, treatment of 7 with $\mathrm{NaBH}_{4}$ resulted in the ring-opening and reduced monoadducts 18, which was stable and not active toward BME anymore (Fig. 4d and Supplementary Fig. 26).

Reactivity of 3Br-5MPs upon reaction with peptides and proteins. Next, we investigated the reactivity and cysteine specificity of $3 \mathrm{Br}-5 \mathrm{MPs}$ by carrying out reactions with peptide 19 , which contains only one cysteine, in the middle of the sequence (Table 2). Treatment of peptide 19 with 2 equiv. of $3 \mathbf{a}$ in HEPES buffer ( $\mathrm{pH} 7.5)$ for $5 \mathrm{~min}$ afforded cysteine-modified products in more than $96 \%$ yield at both $37^{\circ} \mathrm{C}$ and $4{ }^{\circ} \mathrm{C}$ (Supplementary Fig. 27). The cysteine-tagging efficiency of $\mathbf{3 a}$ was clearly higher than that of $5 \mathrm{MP}$ analog 5 and was comparable to that of maleimide analog 6 (Table 2). To compare the cysteine specificity of 
a

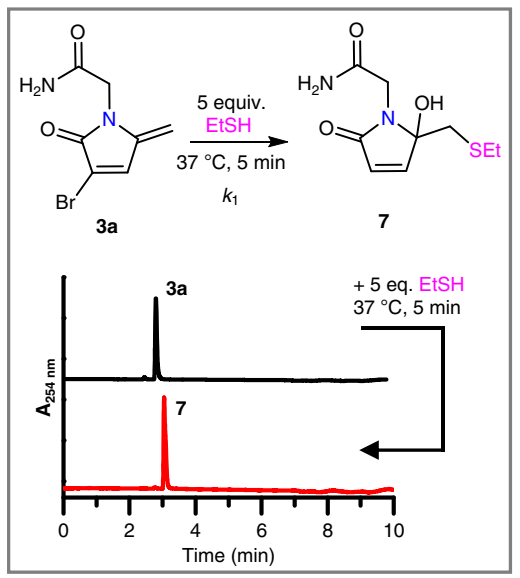

b

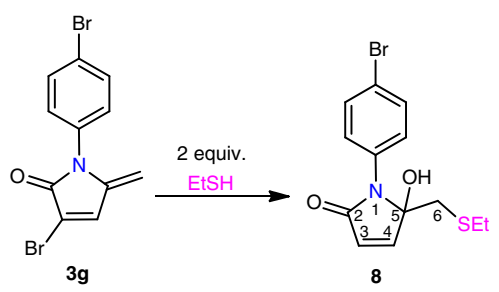

$3 \mathrm{~g}$ c

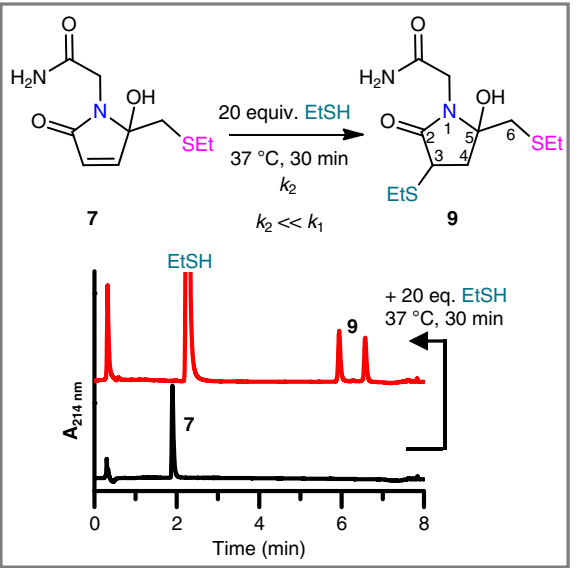

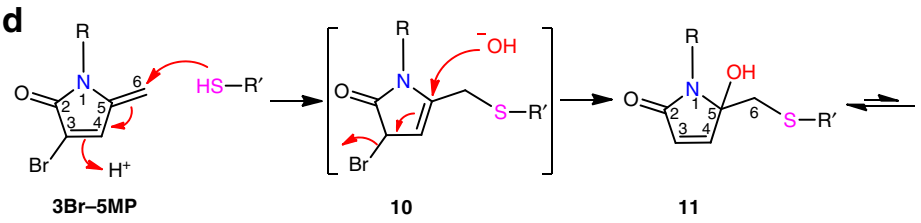

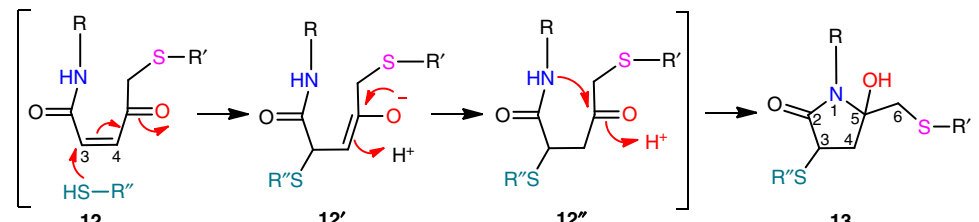

$12^{\prime}$

12

13

Fig. 3 Reactivity of 3Br-5MPs with EtSH in pH 7.5 HEPES buffer. a Reaction of 3a with EtSH. Lower panel, HPLC analysis of the reaction: Column II, O-6 min, MeCN from 5 to 30\%. b Preparation of $\mathbf{8}$ from $\mathbf{3} \mathbf{~ g}$ and EtSH. The crystal structure of $\mathbf{8}$ is shown below. $\mathbf{c}$ Reaction of $\mathbf{7}$ with excess EtSH. Lower panel, HPLC analysis of the reaction: Column I, 0-6 min, MeCN from 5 to 20\%. d Proposed mechanism for the reaction between 3 Br-5MPs with thiols.

$3 \mathrm{Br}-5 \mathrm{MPs}$ with the specificities of maleimide and 5MP, we also treated peptide 19 with a large excess of each substrate (10 equiv.) for $1 \mathrm{~h}$. Ultra-performance liquid chromatography-tandem mass spectrometry (UPLC-MS/MS) analyses showed that the use of $3 \mathrm{Br}-5 \mathrm{MP} 3 \mathrm{a}$ and $5 \mathrm{MP} 5$ led to modification exclusively on the cysteine, whereas the use of maleimide 6 resulted in a $71 \%$ yield of a product that was modified not only on the cysteine residue but also on the N-terminal amino group (Supplementary Fig. 28). That is, the $3 \mathrm{Br}-5 \mathrm{MP}$ showed higher cysteine specificity than maleimide and higher reactivity than $5 \mathrm{MP}$. Moreover, the $3 \mathrm{Br}$ $5 \mathrm{MP}$ retained its excellent reactivity and specificity over a broad range of $\mathrm{pH}$ values (6.0-9.5; Supplementary Fig. 29).

The high reactivity and specificity of the $3 \mathrm{Br}-5 \mathrm{MPs}$ were confirmed by experiments with a histone $\mathrm{H} 3$ mutant, H3-V35C (20), which contains only one cysteine (at position 35). Reactions of 20 with 2 equiv. of $\mathbf{3 a - f}$ in HEPES buffer ( $\mathrm{pH}$ 7.5) were complete within $1 \mathrm{~h}$, as indicated by UPLC-MS (Supplementary Fig. 30).

Next, we studied reactions between the mono-adduct 7 and peptide 19 to interrogate the efficiency of further modification of the primary conjugate by cysteine (Table 2). Incubation of peptide 19 with 2 equiv. of 7 at $37^{\circ} \mathrm{C}$ for $5 \mathrm{~min}$ led to a $<1 \%$ yield of the conjugated product and the yield increased to $15 \%$ when the reaction time was increased to $1 \mathrm{~h}$. When 10 equiv. of 6 was used, the reaction was complete after $1 \mathrm{~h}$ and the Cys-modified conjugate was the sole product (Table 2 and Supplementary Figs. 27 and 28). These observations, consistent with the above model studies, indicate that primary conjugate 7 was highly specific for cysteine modification, but its reactivity was remarkably lower than that of the $3 \mathrm{Br}-5 \mathrm{MPs}$. These results demonstrate that if the ratio of reagents and the reaction conditions are carefully controlled, $3 \mathrm{Br}-5 \mathrm{MPs}$ can be used not only for cysteine-specific mono-functionalization but also for stepwise multi-functionalization of a single cysteine and disulfide bridging bioconjugation.

Multi-functionalization of proteins with 3Br-5MPs. We demonstrated the efficiency of protein multi-functionalization using 3Br-5MPs by tagging H3-V35C (20) with both fluorescein and biotin in a stepwise fashion (Fig. 5a). Specifically, reaction of 20 with 2 equiv. of $3 \mathbf{e}$ in HEPES buffer $\left(\mathrm{pH} \mathrm{7.5)}\right.$ at $37^{\circ} \mathrm{C}$ for $1 \mathrm{~h}$ quantitatively gave fluorescein-modified product $\mathbf{2 1}$ as the sole product. Without purification, the reaction mixture was treated with 7 equiv. of biotin-SH (22), which was then incubated for $2 \mathrm{~h}$. Doubly labeled product $\mathbf{2 3}$ was obtained in yields up to $95 \%$ (Supplementary Fig. 31).

To assess the stability of the doubly labeled conjugate, we incubated the purified 23 in HEPES buffer $(\mathrm{pH} 7.5)$ at $37^{\circ} \mathrm{C}$. Aliquots were periodically withdrawn and subjected to SDSpolyacrylamide gel electrophoresis analysis. Fluorescence imaging of the gel showed that the fluorescein group was firmly attached on the protein, whereas slow release of the biotin group (via retro-Michael reaction) was observed, as quantified both by immunoblotting with biotin antibody and by MS (Supplementary Fig. 32). Addition of $1 \mathrm{mM}$ glutathione to the incubation buffer markedly increased the rate of biotin release (Fig. 5b) and a glutathione-tagged product $\mathbf{2 4}$ was obtained through thiol exchange (Supplementary Fig. 32). Hence, just like the model 
$\mathbf{a}$

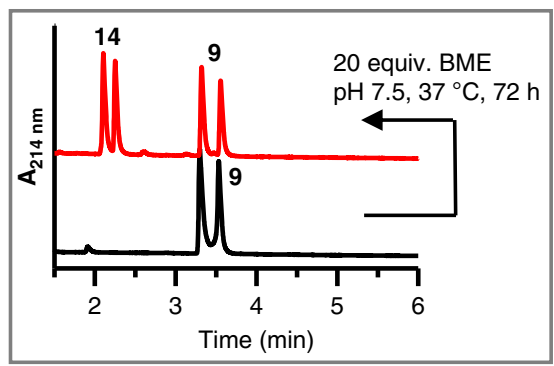

b<smiles></smiles><smiles>CCCC1(O)C[C@H](SCCO)C(=O)N1CC(N)=O</smiles>

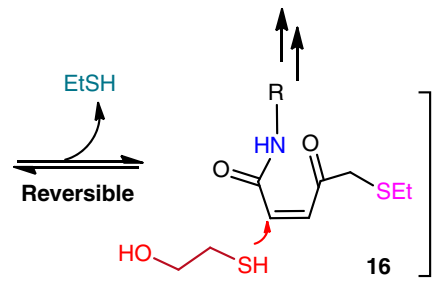

c

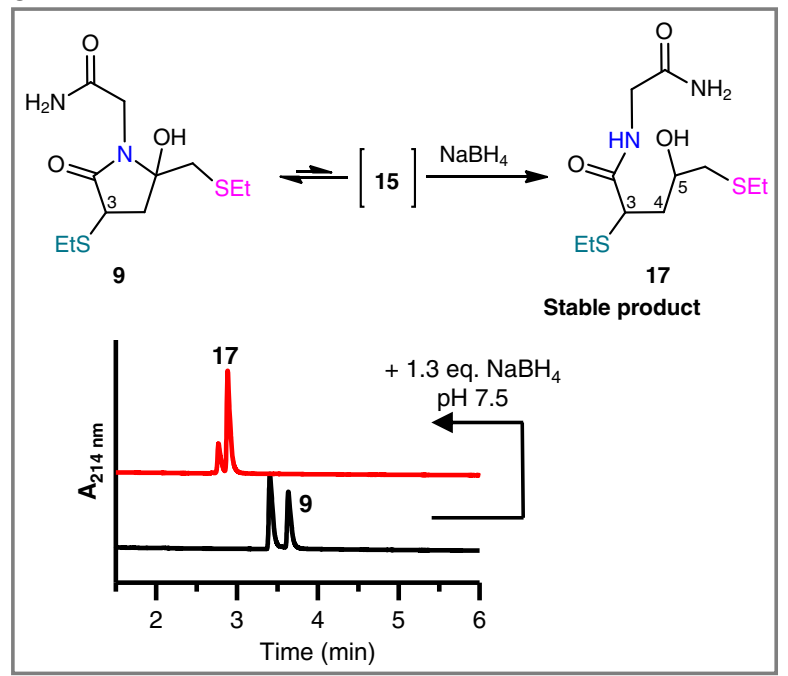

d

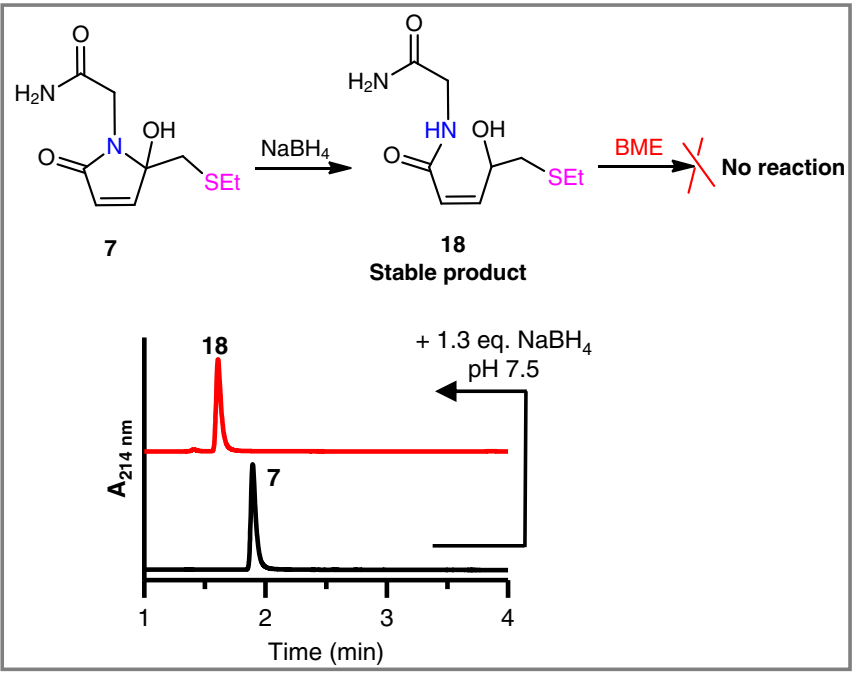

Fig. 4 Stability and reactivity of EtSH-3Br-5MP adducts 7 and 9. a HPLC analyses of the thiol-exchange reaction of 9 in the presence of excess BME: Column I, 0-6 min, MeCN from 5 to 50\%. b Proposed mechanism of thiol-exchange reaction of $\mathbf{9}$. c Reduction of $\mathbf{9}$ by $\mathrm{NaBH}_{4}$ to stabilize the dual-adduct $\mathbf{9}$. Lower panel, HPLC analysis of the reduction reaction: Column I, 0-6 min, MeCN from 5 to $50 \%$. d Reduction of $\mathbf{7}$ by $\mathrm{NaBH}_{4}$ to abolish its further reactivity toward thiols. Lower panel, HPLC analysis of the reduction reaction: Column I, 0-6 min, MeCN from 5 to $20 \%$.

Table 2 Reactivities of substrates 3a, 5-7 upon treatment with peptide 19.

Equiv.


a

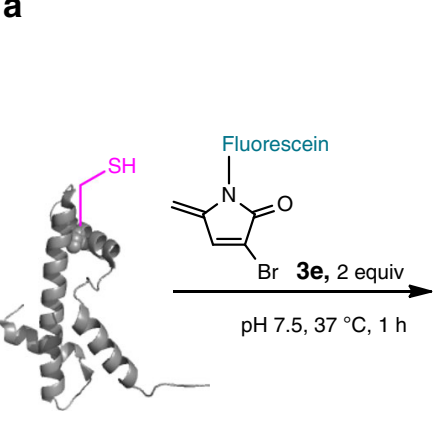

H3-V35C

20

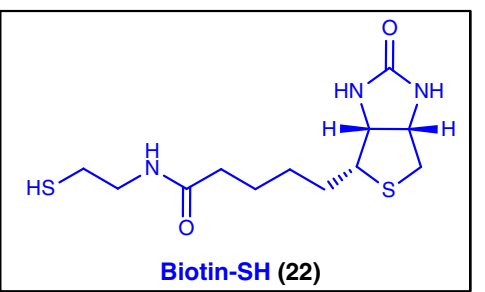

Biotin-SH (22)

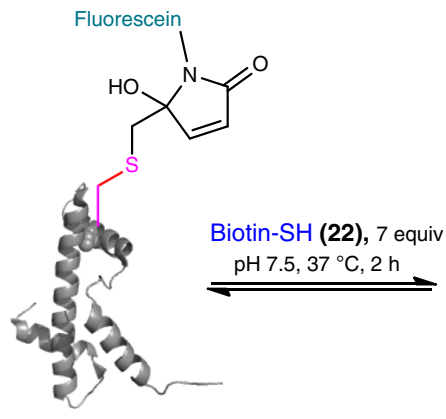

21

$3 \mathrm{mM} \mathrm{NaBH}$ HEPES, pH 7.5

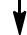

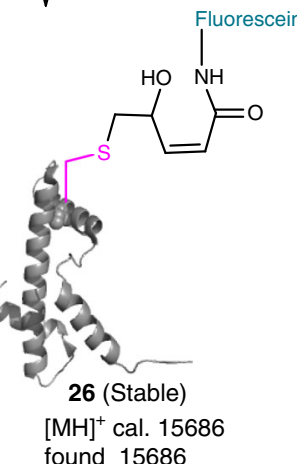

found 15686

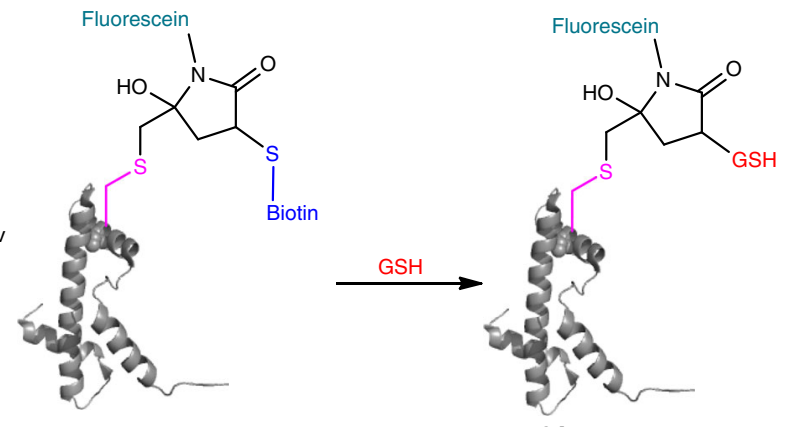

23 $3 \mathrm{mM} \mathrm{NaBH}_{4}$ HEPES, $\mathrm{pH} 7.5$

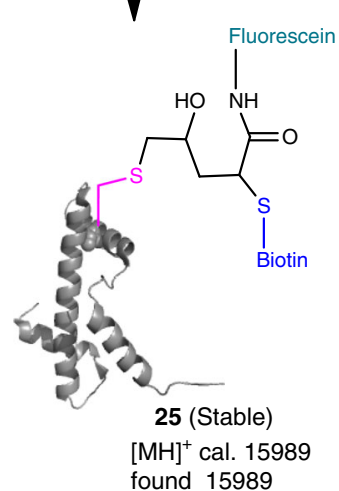

b

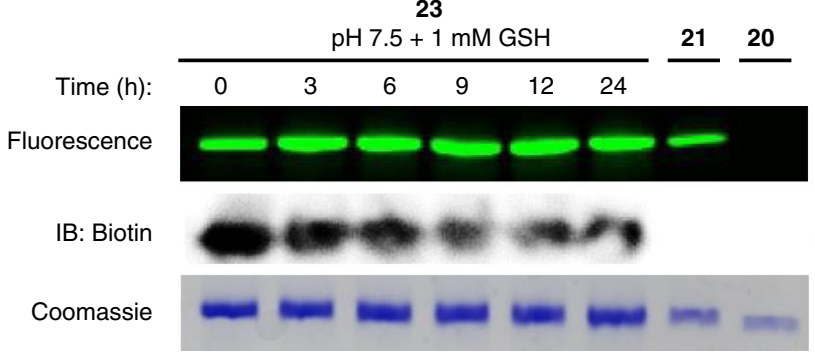

C

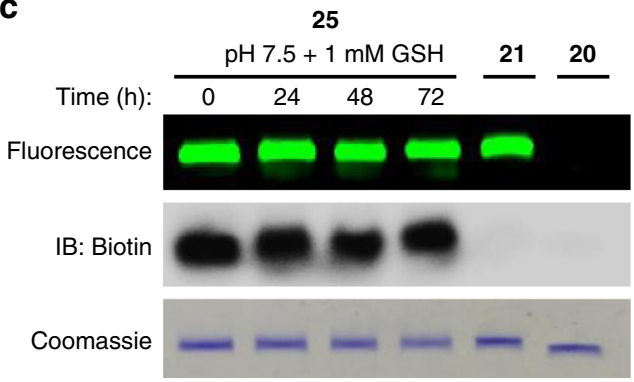

Fig. 5 Mono- and multi-functionalization of proteins using $\mathbf{3 B r - 5 M P s . ~ a ~ A ~ s c h e m a t i c ~ r e p r e s e n t a t i o n ~ o f ~ m o n o - ~ a n d ~ m u l t i - f u n c t i o n a l i z a t i o n ~ o f ~} \mathrm{H} 3-\mathrm{V} 35 \mathrm{C}$ (20). b Fifteen percent SDS-PAGE analysis of the stability of the doubly modified product $\mathbf{2 3}$ upon incubation with $1 \mathrm{mM}$ GSH in $\mathrm{HEPES}$ buffers ( $\mathrm{pH} 7.5$ ). c Fifteen percent SDS-PAGE analysis of the stability of the reduced doubly modified product $\mathbf{2 5}$ upon incubation with $1 \mathrm{mM}$ GSH in $\mathrm{HEPES}$ buffers ( $\mathrm{pH} 7.5$ ). Source data are provided as a Source Data file.

compound $\mathbf{9}$, the dual-functionalized protein conjugate $\mathbf{2 3}$ was liable to loss of the secondary modification via thiol-exchange reaction.

We have shown that reduction of 9 by $\mathrm{NaBH}_{4}$ can transform it into stable dual-adducts. In neutral buffers, $\mathrm{NaBH}_{4}$ is a mild reductant and is used for selective reduction of disulfide bonds in proteins $^{41-43}$. We treated the protein H3-V35C (20) with different concentrations of $\mathrm{NaBH}_{4}$ in HEPES buffer ( $\mathrm{pH}$ 7.5) and found that $\mathrm{NaBH}_{4}$ concentration as low as $3 \mathrm{mM}$ rendered no adverse effects for the protein H3-V35C (Supplementary Fig. 33). Thus, 23 was treated with $3 \mathrm{mM}$ (30 equiv.) $\mathrm{NaBH}_{4}$ in HEPES buffer ( $\mathrm{pH}$ 7.5) and reduced conjugate 25 was obtained (Supplementary Fig. 34). Compound 25 was stable for up to 3 days in a neutral buffer, even in the presence of glutathione (Fig. 5c). The tagging of both fluorescein and biotin on the Cys35 was confirmed at this stage based on MS/MS mapping of the tryptic fragments of 25 (Supplementary Fig. 35). In addition, treatment of mono-functionalized conjugate 21 with $3 \mathrm{mM}$ $\mathrm{NaBH}_{4}$ yielded 26 (Supplementary Fig. 36), which was stable and not reactive toward biotin-SH (Supplementary Fig. 37) Hence, reduction of protein-3Br-5MP mono-adducts with $\mathrm{NaBH}_{4}$ abolishes their further reactivity toward thiols. This represents an efficient approach to prepare stable and mono-functionalized protein conjugates.

Disulfide bridging bioconjugation using 3Br-5MPs. We demonstrated the feasibility of disulfide bridging bioconjugation with $3 \mathrm{Br}-5 \mathrm{MPs}$ by using the endogenous hormone somatostatin $(\mathrm{SST})^{29,31}$, which contains a single disulfide bridge. Reduction of the disulfide bond of SST $(0.05 \mathrm{mM})$ with 1.5 equiv. of tris(2carboxyethyl)phosphine (TCEP) in HEPES buffer ( $\mathrm{pH} 7.5)$ and subsequent addition of 1.3 equiv. of $3 \mathrm{Br}-5 \mathrm{MP} 3 \mathbf{a}$ or $3 \mathbf{e}$ led to disulfide-rebridging product $\mathbf{2 7}$ or $\mathbf{2 8}$, respectively, in quantitative yield (Fig. 6a and Supplementary Fig. 38). It is worth noting that the obtained rebidging products are a mixture of regioisomers, depending on which cysteine reacted first with 3Br-5MP. Both 27 and $\mathbf{2 8}$ could be converted to the corresponding reduced product 


\section{a}
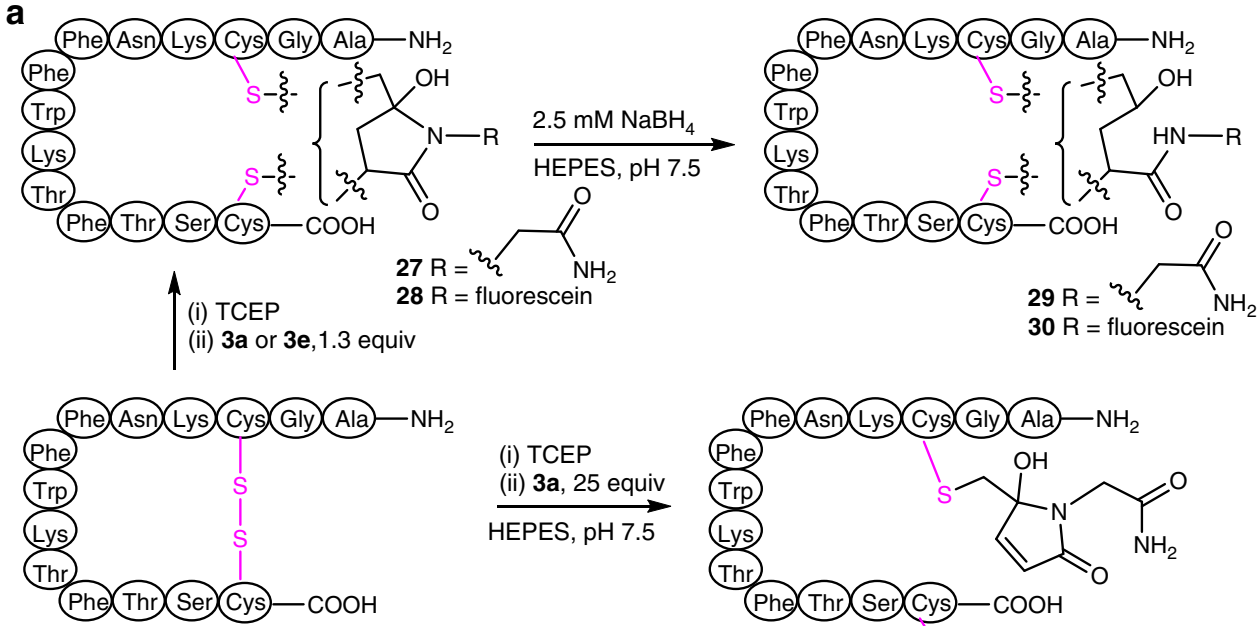

(i) TCEP
$\underset{\text { (ii) } 3 a, 25 \text { equiv }}{\stackrel{\text { HEPES, pH } 7.5}{\longrightarrow}}$

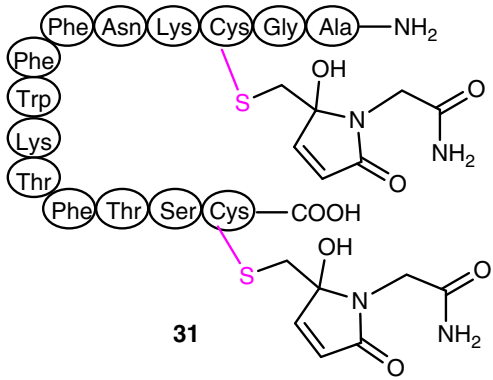

Somatostatin (SST), $0.05 \mathrm{mM}$

b

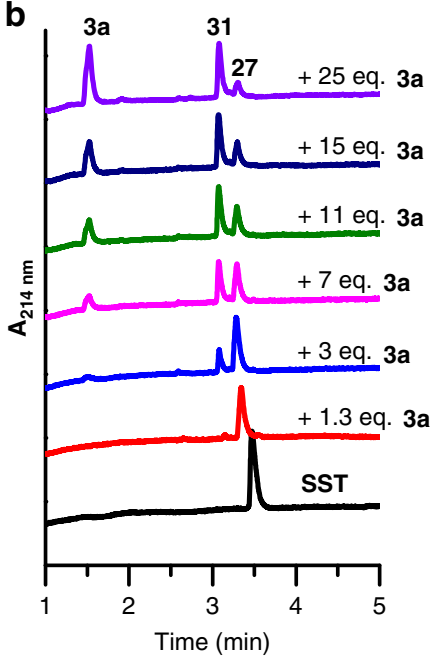

C

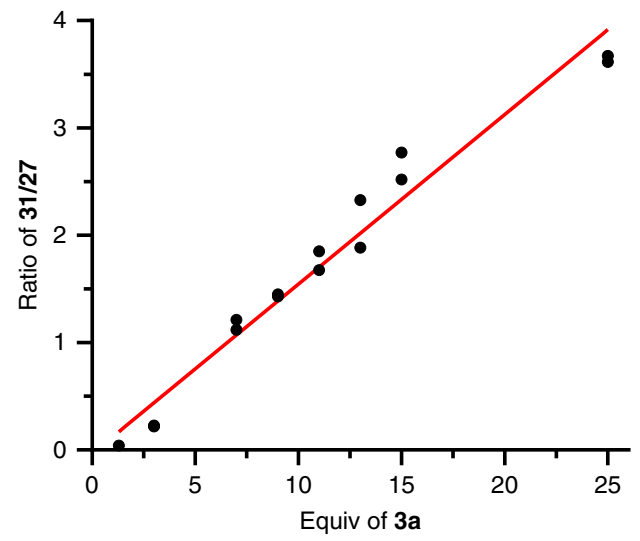

Fig. 6 Disulfide bridging bioconjugation of somatostatin with 3Br-5MPs. a Synthesis of somatostatin (SST) bridged by 3Br-5MPs. b UPLC analysis of the reactions between reduced SST and various amounts of $\mathbf{3 a}$. c Relationship between 31/27 ratio and amount of $\mathbf{3 a}$. Data points from two independent experiments are shown here. Source data are provided as a Source Data file.

(29 or 30, respectively) by direct addition of $2.5 \mathrm{mM}$ (50 equiv.) $\mathrm{NaBH}_{4}$. Purified 29 and 30 were subjected to Ellman's test, which showed that they contained no free thiol groups, thus confirming that the $3 \mathrm{Br}-5 \mathrm{MPs}$ were attached to SST via disulfide bridging (Supplementary Fig. 38).

In the presence of a relatively small amount of $\mathbf{3 a}$ ( $<1.3$ equiv.), disulfide bridging bioconjugation of SST was efficient and doubly modified product $\mathbf{3 1}$ was not detected. However, increasing the amount of $\mathbf{3 a}$ decreased the yield of $\mathbf{2 7}$ and led to the formation of 31 (Fig. 6b and Supplementary Fig. 39), the yield of which increased as the amount of 3a was increased. The 31/27 ratio was linearly correlated with the amount of $\mathbf{3 a}$ (Fig. $6 \mathrm{c}$ ). These results indicate that after disulfide reduction, $3 \mathrm{Br}-5 \mathrm{MPs}$ could be used not only for bridging bioconjugation but also for modification of two free cysteines and the product selectivity could be easily controlled by adjusting the amount of the $3 \mathrm{Br}-5 \mathrm{MP}$.

Next, we demonstrated the practicability of preparing antibody conjugates by disulfide bridging with a $3 \mathrm{Br}-5 \mathrm{MP}$ and the antigenbinding fragment (Fab) of goat antibody anti-human IgG (Fig. 7a). The Fab fragment contains two chains that are covalently linked by one interchain disulfide bond. Treatment of the goat Fab fragment $(0.5 \mathrm{mg} / \mathrm{mL})$ in phosphate buffer $(20$ $\mathrm{mM}, \mathrm{pH} 8.2)$ with dithiothreitol $(0.56 \mathrm{mM}, 40$ equiv.) led to chemoselective cleavage of the interchain disulfide (Fig. 7b, lane $3)^{44,45}$. After removal of excess dithiothreitol by gel filtration, 3Br-5MP 3e ( $0.02 \mathrm{mM}, 1.4$ equiv.) was added and the reaction mixture was incubated at $37^{\circ} \mathrm{C}$ for $1 \mathrm{~h}$ to generate fluoresceinmodified Fab fragment 32. The modified fragment migrated to the same place as the intact fragment (Fig. 7b, lane 5) and the degree of labeling of this conjugate was determined to be approximately 1.1 based on UV-Vis spectrum (Supplementary Fig. 40), suggesting that the two chains were covalently linked by disulfide rebridging via 3e. In situ reduction by $\mathrm{NaBH}_{4}(3 \mathrm{mM})$ converted 32 to stable conjugate 33. Given that intrachain disulfides are also reducible by $\mathrm{NaBH}_{4}{ }^{42,43}$, we carried out a mild oxidation step using dehydrogenated ascorbic acid $(0.14 \mathrm{mM})^{45}$ to restore the intrachain disulfide bond (Fig. 7b, lane 7).

To evaluate the biological activity of antibody conjugate 33 , we treated cancer cell line SK-BR-3, which expresses high levels of HER2 on the cell surface, with HER2 antibody human IgG trastuzumab and then with $33^{46}$. Fluorescence imaging of the treated cells showed strong fluorescence on the cell surface 
a

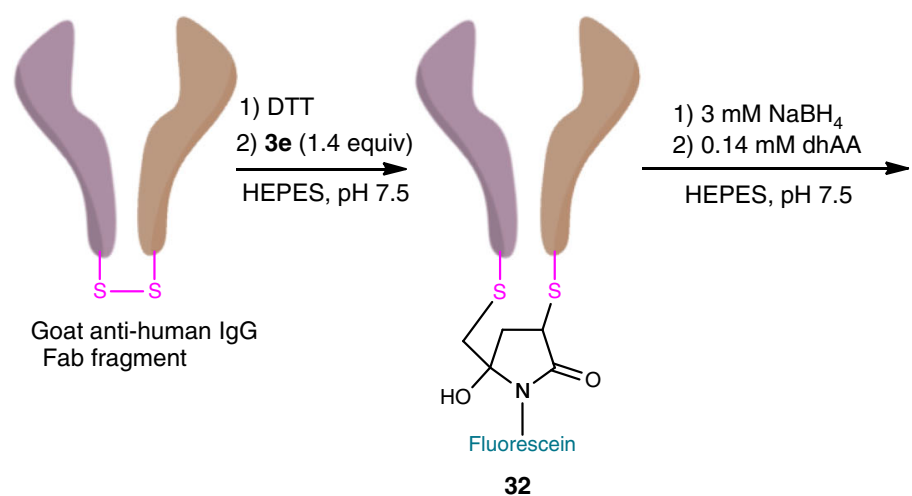

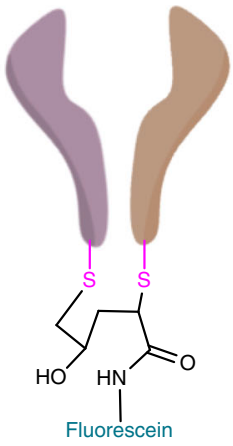

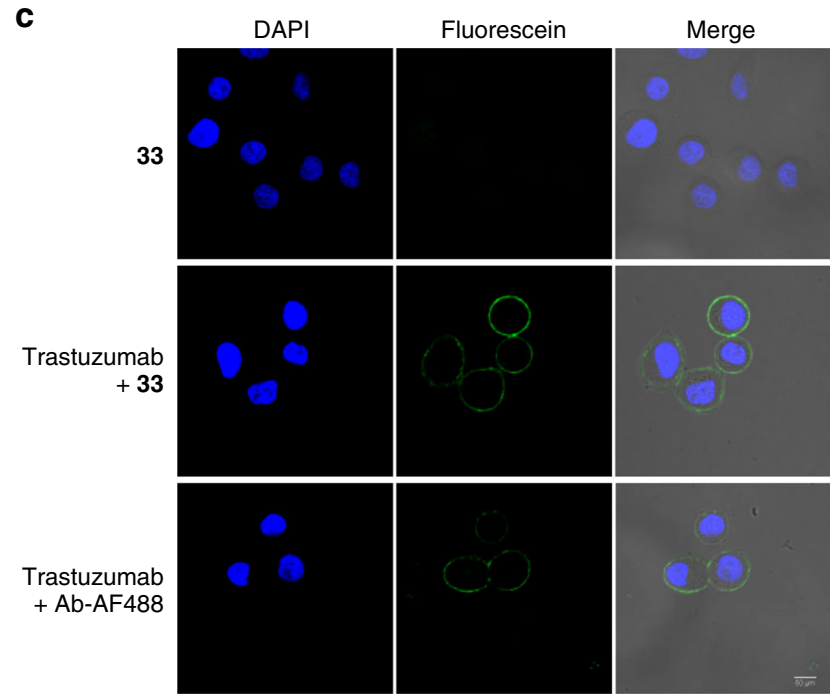

33

1) $3 \mathrm{mM} \mathrm{NaBH}_{4}$

Fluorescein

33 b
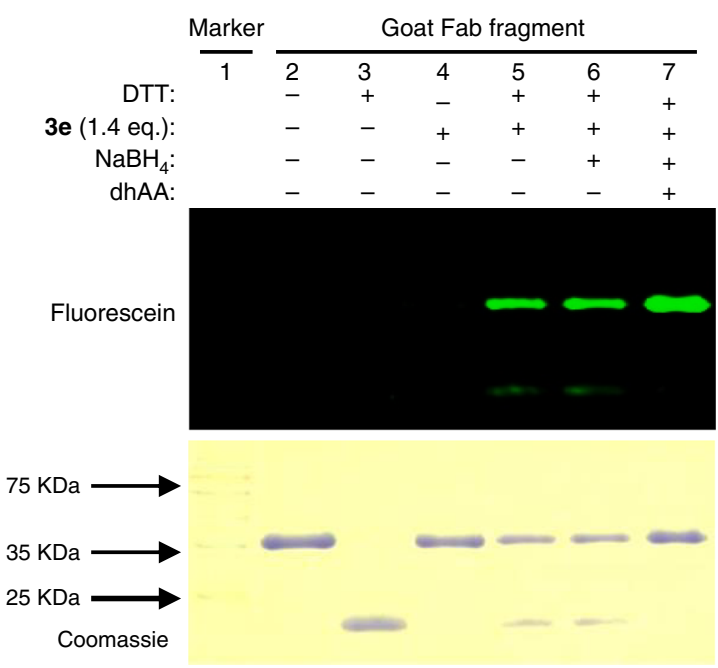

Fig. 7 Disulfide bridging bioconjugation of an antibody fragment with 3Br-5MP 3e. a Strategy for disulfide bridging bioconjugation of the Fab fragment of goat anti-human IgG via 3Br-5MP. b SDS-PAGE gel analysis of disulfide bridging bioconjugation of the Fab fragment, with fluorescence imaging (top gels) and Coomassie staining (bottom gels). c Biological activity of bridged bioconjugate 33. Trastuzumab binding to HER2 on the surface of SK-BR-3 cells was immunodetected with $\mathbf{3 3}$ (second row). Goat anti-human antibody-Alexa488 conjugate (Ab-AF488) at an equivalent concentration was used as a positive control (third row) and an experiment in the absence of trastuzumab was carried out as a negative control (first row). Scale bar, $50 \mu \mathrm{m}$.

(Fig. 7c, second row), just as was the case for a positive control experiment in which commercial goat anti-human antibodyAlexa488 conjugate (Ab-AF488) was used as the second antibody. These results indicate that protein modification with the $3 \mathrm{Br}$ $5 \mathrm{MP}$, along with reduction with $\mathrm{NaBH}_{4}$ and oxidation with dehydrogenated ascorbic acid, was mild enough to produce active conjugates for biological applications.

\section{Discussion}

In this study, we demonstrated that $3 \mathrm{Br}-5 \mathrm{MPs}$, which are analogs of $5 \mathrm{MPs}$ and maleimides, nevertheless exhibit different cysteinespecific protein bioconjugation behavior. $3 \mathrm{Br}-5 \mathrm{MPs}$ combine the merits of both $5 \mathrm{MPs}$ and maleimides, including easy preparation, good stability, high reactivity, and excellent cysteine specificity. Addition of cysteine to $3 \mathrm{Br}-5 \mathrm{MPs}$ generates conjugates that are amenable to secondary addition by another thiol or cysteine, making 3Br-5MPs valuable for multi-functionalization of a single cysteine and for disulfide bridging bioconjugation. Strikingly, the secondary addition is considerably slower than the primary one, which allows for the controlled preparation of mono-, multifunctionalized proteins or disulfide-bridged conjugates via adjusting the ratio of reagents and reaction conditions. Therefore, we contend that $3 \mathrm{Br}-5 \mathrm{MPs}$ are simple, robust, and versatile reagents for cysteine-specific bioconjugation.
The conjugates obtained by reactions with $3 \mathrm{Br}-5 \mathrm{MPs}$ can be reduced to generate stable products. The labeling reaction and subsequent reduction are mild enough to produce active conjugates for biological applications. Research on preparation of homogeneous antibody-drug conjugates with an ideal drug-toantibody ratio via disulfide bridging bioconjugation using $3 \mathrm{Br}$ $5 \mathrm{MPs}$ and elucidation of their pharmacokinetic and pharmacodynamic properties is ongoing in our laboratory.

\section{Methods}

General procedure for one-pot synthesis of 3Br-5MPs (Method 2). To a solution of $4(100.0 \mathrm{mg}, 0.46 \mathrm{mmol}, 1.0$ equiv.) in $10.0 \mathrm{~mL}$ of solvent $(5.0 \mathrm{~mL}$ tetrahydrofuran (THF) $+5.0 \mathrm{~mL}$ of $0.25 \mathrm{M}$ sodium phosphate buffer $\mathrm{pH} 7.5), \mathrm{N}$ bromosuccinimide ( $98.0 \mathrm{mg}, 0.55 \mathrm{mmol}, 1.2$ equiv.) was added. After the solution was stirred for $1 \mathrm{~h}$ at $0{ }^{\circ} \mathrm{C}$, amine substrate $2(0.55 \mathrm{mmol}, 1.2$ equiv.) was added and the reaction was stirred for $4 \mathrm{~h}$ at room temperature. The reaction mixture was concentrated and then subjected to purification by flash chromatography or high performance liquid chromatography.

Preparation of dual-functionalized protein conjugate (25). A mixture of $3 \mathrm{e}$ $(200 \mu \mathrm{M})$ and H3-V35C $(100 \mu \mathrm{M})$ in HEPES buffer $(20 \mathrm{mM}, \mathrm{pH} 7.5,100 \mathrm{mM}$ $\mathrm{NaCl})$ was incubated at $37^{\circ} \mathrm{C}$ for $1 \mathrm{~h}$. Without purification, Biotin-SH $(22,700 \mu \mathrm{M})$ was added to the solution mixture directly followed by incubation at $37^{\circ} \mathrm{C}$ for $2 \mathrm{~h}$. Freshly prepared $\mathrm{NaBH}_{4}$ solution $(100 \mathrm{mM}$ in water) was added directly into the reaction mixture (final concentration $3 \mathrm{mM}$ ) and incubated at $37^{\circ} \mathrm{C}$ for $40 \mathrm{~min}$. Then excess small molecules and salts were removed by PD Minitrap G-25 column (GE Healthcare). 
Disulfide bridging bioconjugation of SST using 3Br-5MP. A mixture of TCEP $(0.075 \mathrm{mM}, 1.5$ equiv. $)$ and hormone SST $(0.05 \mathrm{mM})$ in HEPES buffer $(20 \mathrm{mM}, \mathrm{pH}$ $7.5,100 \mathrm{mM} \mathrm{NaCl}$ ) was incubated at $37^{\circ} \mathrm{C}$ for $2 \mathrm{~h}$. Without purification, $3 \mathbf{a}$ or $3 \mathbf{e}$ $(0.065 \mathrm{mM}, 1.3$ equiv.) were added into the reaction mixture followed by incubation at the same temperature for $1 \mathrm{~h}$. Freshly prepared $\mathrm{NaBH}_{4}$ solution $(100 \mathrm{mM}$ in water) was added (final concentration $3 \mathrm{mM}$ ) followed by incubation for another $40 \mathrm{~min}$. Aliquots were taken and analyzed by UPLC-MS.

Reporting summary. Further information on research design is available in the Nature Research Reporting Summary linked to this article.

\section{Data availability}

Crystal structure for compound $\mathbf{8}$ is available as Supplementary Data 1 and also at the Cambridge Crystallographic Data Centre under accession number CCDC: 1961778. Methods and all relevant data are available in Supplementary Information and from the authors. The source data underlying Figs. 5b, 5c, and $6 c$, and Supplementary Figs. 32a and $37 \mathrm{a}$ are provided as a Source Data file.

Received: 5 November 2019; Accepted: 30 January 2020;

Published online: 21 February 2020

\section{References}

1. Boutureira, O. \& Bernardes, G. J. L. Advances in chemical protein modification. Chem. Rev. 115, 2174-2195 (2015).

2. Koniev, O. \& Wagner, A. Developments and recent advancements in the field of endogenous amino acid selective bond forming reactions for bioconjugation. Chem. Soc. Rev. 44, 5495-5551 (2015).

3. Chalker, J. M., Bernardes, G. J. L. \& Davis, B. G. A "tag-and-modify" approach to site-selective protein modification. Acc. Chem. Res. 44, 730-741 (2011).

4. Weerapana, E., Simon, G. M. \& Cravatt, B. F. Disparate proteome reactivity profiles of carbon electrophiles. Nat. Chem. Biol. 4, 405-407 (2008).

5. Chalker, J. M., Bernardes, G. J. L., Lin, Y. A. \& Davis, B. G. Chemical modification of proteins at cysteine: opportunities in chemistry and biology. Chem. Asian J. 4, 630-640 (2009).

6. Chudasama, V., Maruani, A. \& Caddick, S. Recent advances in the construction of antibody-drug conjugates. Nat. Chem. 8, 114-119 (2016).

7. Tsuchikama, K. \& An, Z. Antibody-drug conjugates: recent advances in conjugation and linker chemistries. Protein Cell 9, 33-46 (2018).

8. Kalia, D., Malekar, P. V. \& Parthasarathy, M. Exocyclic olefinic maleimides: Synthesis and application for stable and thiol-selective bioconjugation. Angew. Chem. Int. Ed. Engl. 55, 1432-1435 (2016).

9. Kalia, D., Pawar, S. P. \& Thopate, J. S. Stable and rapid thiol bioconjugation by light-triggered thiomaleimide ring hydrolysis. Angew. Chem. Int. Ed. Engl. 56, 1885-1889 (2017).

10. Zhang, Y. et al. Thiol specific and tracelessly removable bioconjugation via Michael addition to 5-methylene pyrrolones. J. Am. Chem. Soc. 139, 6146-6151 (2017).

11. Chalker, J. M. et al. Methods for converting cysteine to dehydroalanine on peptides and proteins. Chem. Sci. 2, 1666-1676 (2011).

12. Wright, T. H. \& Davis, B. G. Post-translational mutagenesis for installation of natural and unnatural amino acid side chains into recombinant proteins. Nat. Protoc. 12, 2243-2250 (2017).

13. Spokoyny, A. M. et al. A perfluoroaryl-cysteine snar chemistry approach to unprotected peptide stapling. J. Am. Chem. Soc. 135, 5946-5949 (2013).

14. Zhang, C. et al. Pi-clamp-mediated cysteine conjugation. Nat. Chem. 8, 120-128 (2016).

15. Evans, E. D. \& Pentelute, B. L. Discovery of a 29 -amino-acid reactive abiotic peptide for selective cysteine arylation. ACS Chem. Biol. 13, 527-532 (2018).

16. Embaby, A. M., Schoffelen, S., Kofoed, C., Meldal, M. \& Diness, F. Rational tuning of fluorobenzene probes for cysteine-selective protein modification. Angew. Chem. Int. Ed. 57, 8022-8026 (2018).

17. Vinogradova, E. V., Zhang, C., Spokoyny, A. M., Pentelute, B. L. \& Buchwald, S. L. Organometallic palladium reagents for cysteine bioconjugation. Nature 526, 687-691 (2015).

18. Kubota, K., Dai, P., Pentelute, B. L. \& Buchwald, S. L. Palladium oxidative addition complexes for peptide and protein cross-linking. J. Am. Chem. Soc. 140, 3128-3133 (2018).

19. Hoyt, E. A., Cal, P. M. S. D., Oliveira, B. L. \& Bernardes, G. J. L. Contemporary approaches to site-selective protein modification. Nat. Rev. Chem. 3, 147-171 (2019).

20. Luo, Q., Tao, Y., Sheng, W., Lu, J. \& Wang, H. Dinitroimidazoles as bifunctional bioconjugation reagents for protein functionalization and peptide macrocyclization. Nat. Commun. 10, 142 (2019).
21. Tessier, R. et al. "Doubly orthogonal" labeling of peptides and proteins. Chem 5, 2243-2263 (2019).

22. Canovas, C. et al. Site-specific dual labeling of proteins on cysteine residues with chlorotetrazines. Angew. Chem. Int. Ed. 57, 10646-10650 (2018).

23. Su, X.-C. \& Chen, J.-L. Site-specific tagging of proteins with paramagnetic ion for determination of protein structures in solution and in cells. Acc. Chem. Res. 52, 1675-1686 (2019).

24. Wang, T. et al. Water-soluble allyl sulfones for dual site-specific labelling of proteins and cyclic peptides. Chem. Sci. 7, 3234-3239 (2016).

25. Maruani, A. et al. A plug-and-play approach to antibody-based therapeutics via a chemoselective dual click strategy. Nat. Commun. 6, 6645 (2015).

26. Badescu, G. et al. Bridging disulfides for stable and defined antibody drug conjugates. Bioconjugate Chem. 25, 1124-1136 (2014).

27. Lee, M. T. W., Maruani, A., Baker, J. R., Caddick, S. \& Chudasama, V. Nextgeneration disulfide stapling: reduction and functional re-bridging all in one. Chem. Sci. 7, 799-802 (2016).

28. Walsh, S. J. et al. A general approach for the site-selective modification of native proteins, enabling the generation of stable and functional antibody-drug conjugates. Chem. Sci. 10, 694-700 (2019).

29. Smith, M. E. B. et al. Protein modification, bioconjugation, and disulfide bridging using bromomaleimides. J. Am. Chem. Soc. 132, 1960-1965 (2010).

30. Jones, M. W. et al. Polymeric dibromomaleimides as extremely efficient disulfide bridging bioconjugation and pegylation agents. J. Am. Chem. Soc 134, 1847-1852 (2012).

31. Chudasama, V. et al. Bromopyridazinedione-mediated protein and peptide bioconjugation. Chem. Commun. 47, 8781-8783 (2011)

32. Maruani, A. et al. A mild TCEP-based para-azidobenzyl cleavage strategy to transform reversible cysteine thiol labelling reagents into irreversible conjugates. Chem. Commun. 51, 5279-5282 (2015).

33. Lee, M. T. W. et al. Enabling the controlled assembly of antibody conjugates with a loading of two modules without antibody engineering. Chem. Sci. 8, 2056-2060 (2017).

34. Wang, T. et al. Cross-conjugation of DNA, proteins and peptides via a $\mathrm{pH}$ switch. Chem. Sci. 4, 1889-1894 (2013).

35. Zang, C. et al. A light-responsive, self-immolative linker for controlled drug delivery via peptide- and protein-drug conjugates. Chem. Sci. 10, 8973-8980 (2019).

36. Jacinto, M. P., Pichling, P. \& Greenberg, M. M. Synthesis of 5-methylene-2pyrrolones. Org. Lett. 20, 4885-4887 (2018).

37. Halila, S., Velasco, T., De Clercq, P. \& Madder, A. Fine-tuning furan toxicity: Fast and quantitative DNA interchain crosslink formation upon selective oxidation of a furan containing oligonucleotide. Chem. Commun. 936-938 (2005).

38. Fontaine, S. D., Reid, R., Robinson, L., Ashley, G. W. \& Santi, D. V. Long-term stabilization of maleimide-thiol conjugates. Bioconjugate Chem. 26, 145-152 (2015).

39. Liu, Y. et al. Thio-michael addition of $\alpha, \beta$-unsaturated amides catalyzed by Nmm-based ionic liquids. RSC Adv. 7, 43104-43113 (2017).

40. Böhme, A., Thaens, D., Paschke, A. \& Schüürmann, G. Kinetic glutathione chemoassay to quantify thiol reactivity of organic electrophiles-application to a, $\beta$-unsaturated ketones, acrylates, and propiolates. Chem. Res. Toxicol. 22, 742-750 (2009)

41. Badescu, G. et al. A new reagent for stable thiol-specific conjugation. Bioconjugate Chem. 25, 460-469 (2014).

42. Duane Brown, W. Reduction of protein disulfide bonds by sodium borohydride. Biochim. Biophys. Acta 44, 365-367 (1960).

43. Jocelyn, P. C. Chemical reduction of disulfides. Methods Enzymol. 143, 246-256 (1987)

44. Khalili, H., Godwin, A., Choi, J. W., Lever, R. \& Brocchini, S. Comparative binding of disulfide-bridged peg-fabs. Bioconjugate Chem. 23, 2262-2277 (2012).

45. Junutula, J. R. et al. Site-specific conjugation of a cytotoxic drug to an antibody improves the therapeutic index. Nat. Biotechnol. 26, 925-932 (2008)

46. Ohata, J. \& Ball, Z. T. A hexa-rhodium metallopeptide catalyst for site-specific functionalization of natural antibodies. J. Am. Chem. Soc. 139, 12617-12622 (2017).

\section{Acknowledgements}

This work was supported by the National Natural Science Foundation of China (21877064 and 91953115 to C.Z.Z. and 21740002 to Z.X.) and by the National Key R\&D Program of China (2017YFD0200501 to Z.X.)

\section{Author contributions}

Y.Q.Z. performed most of the biochemical experiments regarding protein modifications C.L.Z. designed and carried out the chemical synthesis and mechanism studies. G.C.A., M.D.S., and Z.H.C. took part in the chemical synthesis and biochemical experiments. G.C. and Z.X. contributed new reagents/analytic tools. C.Z.Z. designed and supervised 
the project. Y.Q.Z., C.L.Z., and C.Z.Z. wrote the manuscript. All authors have given approval to the final version of the manuscript.

\section{Competing interests}

The authors declare no competing interests.

\section{Additional information}

Supplementary information is available for this paper at https://doi.org/10.1038/s41467020-14757-4.

Correspondence and requests for materials should be addressed to C.Z.Z.

Peer review information Nature Communications thanks Victor Goncalves and the other, anonymous, reviewer(s) for their contribution to the peer review of this work. Peer reviewer reports are available.

Reprints and permission information is available at http://www.nature.com/reprints
Publisher's note Springer Nature remains neutral with regard to jurisdictional claims in published maps and institutional affiliations.

(c) (i) Open Access This article is licensed under a Creative Commons Attribution 4.0 International License, which permits use, sharing, adaptation, distribution and reproduction in any medium or format, as long as you give appropriate credit to the original author(s) and the source, provide a link to the Creative Commons license, and indicate if changes were made. The images or other third party material in this article are included in the article's Creative Commons license, unless indicated otherwise in a credit line to the material. If material is not included in the article's Creative Commons license and your intended use is not permitted by statutory regulation or exceeds the permitted use, you will need to obtain permission directly from the copyright holder. To view a copy of this license, visit http://creativecommons.org/ licenses/by/4.0/.

(C) The Author(s) 2020 